\title{
Applying Combined Efforts of Resource Capability of Project Teams for Planning and Managing Contingency Reserves for Software and Information Engineering Projects
}

\author{
Peter H. Chang, Member, IEEE \\ College of Management \\ Lawrence Technological University \\ Southfield, Michigan 48075, USA \\ pchang@ltu.edu
}

\begin{abstract}
In project management, an important means to reduce risks is to provide adequate quantities of contingency reserve in terms of capital (fund), person, time (person hours), in the estimate of required project resources. Experienced project managers usually provide more accurate estimate of these quantities. The traditional project management methodologies, such as System Development Life Cycle (SDLC), were developed to handle software and information engineering projects of longer duration and larger number of project members. Many projects in modern days have short duration and smaller number of project members. They tend to follow newer methodologies, such as Agile Development, to adapt to the faster changes of modern technologies, processes, and user requirements. For a project manager, gathering information to properly create an effective project plan is like identifying a collection of problems and solving them. Solving problems needs supporting resources, which is analogous to the fact that projects need adequate supporting resources. This paper proposes an approach that applies combined efforts of the resource capabilities of project teams for planning and managing contingency reserves of a modern-day project in software or information engineering.
\end{abstract}

Index Term-project management, contingency, methods of problem solving, reserve, resource capability, software engineering, information engineering

\section{INTRODUCTION}

The term contingency reserve is a common term in project management. The Web site of the Project Management Knowledge [1] defines the phrase contingency reserve as a term that refers to the amount of quantity of time, person, or capital that is reserved to be allocated above the previously estimated amount to reduce the risk of overruns to an acceptable level. In this paper we use the terms of contingency and contingency reserve interchangeably.

For a project manager, gathering information to properly create an effective project plan and successfully execute it is like identifying a collection of problems and solving them.

In 1945, George Pólya, a mathematician, published his classic book "How to Solve It" [2] on the introduction of general methods of problem solving. The book was selected as one of 100 Princeton University Press's Notable Centenary Titles (Princeton University Press [3]) from the year 1905 to the year 2005 for its profound influences to both mathematics discipline and non-mathematics disciplines. A significance of this book is shown by that its title is listed along with the title of Albert Einstein's book "The Meaning of Relativity" as two of the 100 titles.

In 1991, Milner presented his ACM Turing Award lecture on the "Elements of Interaction" [4], which proposes an interactive method of solving computing problems over the traditional sequential approach that is based on Turing machine.

Based on the methods of Pólya and Milner, Chang [5] proposed three elements of methods of problem solving (EMPS) and the rule and scope that complement the elements as shown in Figure 1. The three elements are intrinsic (strategic), semantic (tactical), and syntactic (operational), respectively. Chang et al. [6] proposed a principle of balancing of the resource capabilities that support the elements. These elements are at or near the highest level of abstraction. Various concrete methods may be derived from them that may help solve the modern-day problems.

Many modern-day projects follow some newer methodology of one of the following: Rapid Application Development (RAD), Prototype, Agile Development (Extreme Programming, Scrum), or others. The project durations are in general shorter with smaller number of project members who work at intensive paces; the project team interacts with users more frequently and may need to manage the requests of scope changes by users. Risks such as inadequate planning of contingency reserve may be realized. Some traditional project management methodologies, such as System Development Life Cycle, concentrate at the operational level; they may not be effective in mitigating these risks. The observation in Schenhar [7] supports this notion. He cautioned that methods used in managing some past technical projects may not be applicable to the current projects and that "one size does not 
fit all”. In particular, he presented a two dimensional model in addressing project contingency. The first dimension is about four technology uncertainties. The second dimension is about three system uncertainties. Davis [8] discussed strategies of information requirements determination, which is an early phase of project management life cycle, and stated the following. "There should not be a single approach to requirements determination that is applied to all projects."

For the planning of software projects, Zhang et al. [9] used the method of semi-quantitative reasoning in enhancing the confidence of project success under the uncertainly and contingency. They presented the following common metrics for the success of software projects: cost, quality (defects), scope (functionality), customer satisfaction, market share, return of investment (ROI), and others. Section III of this paper addresses the relationship between resource capability and these metrics. Zhang et al. [9] also illustrated their points by a simplified software process model focusing on staffing issues. Section $\mathrm{V}$ of this paper discussed some examples of using contingencies of project members in handling some unplanned events during the life cycles of projects.

Ropponen et al. [10] analyzed the results of a survey of some software project managers and stated the following. "The analysis results suggest that software risk management is affected by the selection of target platforms, the use of disciplined development process, leveraging on experience, hiring well-educated people, and proper scoping of projects." They also promoted "contingency oriented systems development practices." Section II of this paper discusses the scoping in terms of the EMPS. Section III discusses the requirement of enough education, experience, and efforts of project members.

In discussing the management of contingency reserve, Steyn [11] stated the following. "As a result of the uncertainty and risk inherent to projects, almost all project plans include contingency reserves in budgets as well as in schedules."

In this paper we propose a new approach in applying the resource capabilities supporting the EMPS to the planning of contingency reserves. Some traditional project management tools, such as Microsoft Project, concentrates at the operational level and may not be effective to handle the planning of contingency reserve. In Section V, we discuss scenarios of applying this new approach. A new project management tool may be developed based on this concept.

\section{ELEMENTS OF METHODS}

Chang [5] proposed three layers of elements of EMPS: intrinsic, semantic, and syntactic as shown in Figure 1. These elements vary in degree of abstractions on methods of problem solving in software projects. The rules that need to be followed and the scope of the problem span across the three layers.

An intrinsic element has the highest degree of abstraction. It represents strategic method, internal concepts, paradigm, common understandings, and intuitive thoughts that serve as the base (or core) for some semantic elements. This element is related to an organization's culture into which the project team is embedded.

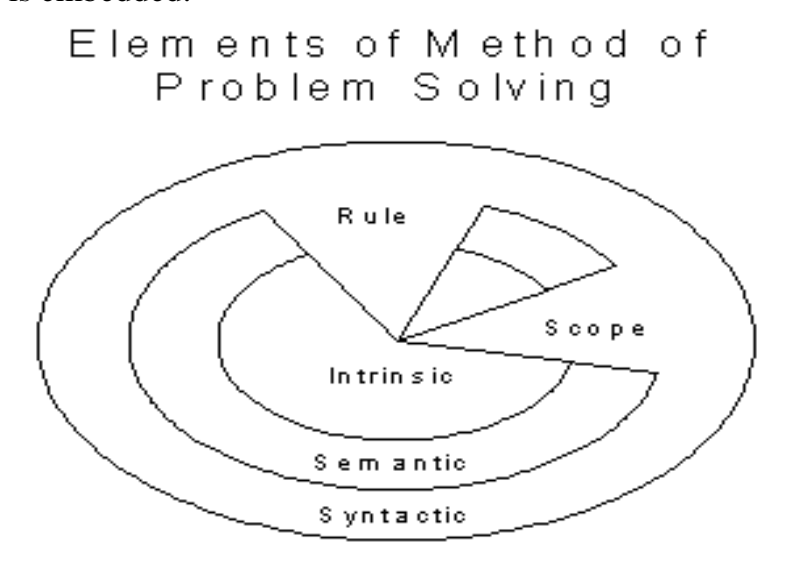

Fig. 1 Elements of Method of Problem Solving

A semantic element represents tactical methods that plan and formulate policies and guidelines based on an intrinsic element in solving project problems.

The syntactic element represents the operational steps that solve project problems. A syntactic element may involve processes, procedures, technologies or tools. This element covers the project team's operations.

\section{RESOURCE CAPABILITY AND CONFLICTS}

As were shown in the layered model of Figure 1, which depicts elements of method of problem solving, rule and scope apply across the layers of the EMPS elements. Both the rule and scope are supported by resource capabilities that consist of time, person, and capital. Time is related to project schedule. Capital is used to pay for project expense. A rule needs time and capital as project members need them to enforce the rules and cover the project expenses. A scope needs time and capital as project members need them to produce the deliverables and cover the project expenses.

A definition of the word: effort is "the total work done to achieve a particular end." In regards to a resource capability as a time or a capital, its utilization must be accompanied by the serious efforts of the entity that uses it. In regards to a resource capability as a person, this person must make serious efforts in doing his or her assigned work. For the rest of this paper, it is assumed that resource capabilities are associated with efforts. The result of the utilization of a resource capability can be measured as work done through the associated effort. A project's budget supports the expenses incurred from all of these efforts. For example, the budget covers the administration expenses throughout the life time of the project. A project member may be a regular employee or a consultant. The budget covers the payments of salary or service fee for project members, including payment for overtime hours. It may cover the capital needed to procure newer computing equipments for project members.

Zhang et al. [9] stated the following. "The most common metrics for software project success include schedule, cost, 
quality (defects), scope (functionality), customer satisfaction, market share, return of investment (ROI), and others." A project needs enough resource capability of time, project members, and capital in order to meet the above metrics. The meaning of enough project members is not subject to their number only. It is also subject to that the project members are well educated, experienced, and motivated to make their best efforts.

As was cited earlier, Steyn [11] stated the following. "As a result of the uncertainty and risk inherent to projects, almost all project plans include contingency reserves in budgets as well as in schedules."

The relationship between resource capability and allocated resource can be expressed in the following formula, hereafter referred to as resource capability formula.

\section{resource capability = allocated resource + reserved resource for contingency}

In term of time or capital, an example for the above formula is that $90 \%$ of it is allocated and $10 \%$ of it is reserved for contingency. In term of project members, two examples for the above formula are presented below. The first example is the following.

$$
\mathrm{N}=\mathrm{A}+\mathrm{RC}
$$

where $\mathrm{N}$ is the total number of available persons who can be assigned to the project, $\mathrm{A}$ is the total number of project members assigned to the project, and RC is the total number of persons reserved for a contingency purpose. For example, A is $90 \%$ of $\mathrm{N}$ and RC is $10 \%$ of $\mathrm{N}$. This example assumes that each project member makes good effort expected by the project management office (PMO).

The second example for the above resource capability formula is about workable overtime hours that project members are capable of working. For a project member, willingness to work overtime is also an effort expected by the PMO.

total number of hours that a project member is capable of working per day $=8$ regular hours + overtime hours

As was cited in Chang [12], Thamhain et al. [13] presented seven categories of conflicts during a project life cycle as schedule, priority, labor requirements, technical factors, administrative procedures, cost estimates, and personality conflict. Table 1 below matches some of these seven categories with the applicable resource contingency that may help resolve the conflicts.

TABLE 1 Category of Project Conflicts

\begin{tabular}{|l|c|c|c|}
\hline Conflict & $\begin{array}{c}\text { Resolvable by } \\
\text { well- planned } \\
\text { resource } \\
\text { contingency }\end{array}$ & $\begin{array}{c}\text { Resource } \\
\text { reserved for } \\
\text { contingency }\end{array}$ & Comment \\
\hline
\end{tabular}

\begin{tabular}{|l|c|c|l|}
\hline Schedule & yes & time & \\
\hline Priority & & & \\
\hline $\begin{array}{l}\text { Labor } \\
\text { requirements }\end{array}$ & yes & person & \\
\hline $\begin{array}{l}\text { Technical } \\
\text { factors }\end{array}$ & may be & person & $\begin{array}{l}\text { Provided } \\
\text { that } \\
\text { experienced } \\
\text { employees or } \\
\text { consultants } \\
\text { are found to } \\
\text { help resolve } \\
\text { the conflict. }\end{array}$ \\
\hline $\begin{array}{l}\text { Administrative } \\
\text { Procedures }\end{array}$ & yes & capital & person \\
\hline Cost estimates & may be & $\begin{array}{l}\text { Provided } \\
\text { that the } \\
\text { cause of the } \\
\text { conflict can } \\
\text { be identified } \\
\text { and that a } \\
\text { resolution is } \\
\text { reached that } \\
\text { benefits the } \\
\text { project. }\end{array}$ \\
\hline
\end{tabular}

As are shown in Table 1, the category of conflicts includes personality conflict. Conflicts of this kind may result in that some project members become unavailable to the project. It is known that the unavailability of project members in a short-term time frame or a long-term time frame is a major barrier for a project manager to keep the project teams meeting the project schedule.

TABLE 2 Scenarios of unavailability of project members

\begin{tabular}{|l|l|l|l|l|}
\hline $\begin{array}{l}\text { Project } \\
\text { Mnavailability } \\
\text { Scenarios }\end{array}$ & $\begin{array}{l}\text { Member } \\
\text { has a } \\
\text { personality } \\
\text { or work } \\
\text { conflict. } \\
\text { But stays } \\
\text { on job. } \\
\text { No short } \\
\text { leave of } \\
\text { absence } \\
\text { needed }\end{array}$ & $\begin{array}{l}\text { Member } \\
\text { returns to } \\
\text { work after } \\
\text { taking a } \\
\text { short leave } \\
\text { of absence. } \\
\text { No } \\
\text { replacement } \\
\text { needed }\end{array}$ & $\begin{array}{l}\text { Member } \\
\text { returns to } \\
\text { work after } \\
\text { being } \\
\text { replaced by a } \\
\text { person on } \\
\text { the list of } \\
\text { contingency } \\
\text { reserves in a } \\
\text { short term } \\
\text { basis }\end{array}$ & $\begin{array}{l}\text { Member's } \\
\text { position } \\
\text { assumed by } \\
\text { a person } \\
\text { reserved on } \\
\text { the list of } \\
\text { contingency } \\
\text { reserves in } \\
\text { a long term } \\
\text { basis }\end{array}$ \\
\hline $\begin{array}{l}\text { Analysts and } \\
\text { designers }\end{array}$ & $\mathrm{X}$ & & & \\
\hline Programmers & & $\mathrm{X}$ & & \\
\hline Testers & & \multicolumn{2}{|c|}{} \\
\hline
\end{tabular}

Table 2 above displays an unavailability scenario in terms of three types of project members in a software project: analysts/designers, programmers, and testers. The event that a member of a certain type becomes unavailable is independent of the event that a member of another type becomes unavailable. Using a statistics method in counting the event multiples, we can determine that the total number of this kind of scenarios is $4 \times 4 \times 4$, which is 64 . In Table 2, the types of project members may be changed and the subject of 
unavailability of project members may be changed to other resource type such as time and capital. Many instances of variations of Table 2 may be derived. It is not an easy task to include all the 64 scenarios in Table 2 in the consideration of project plan in allocating project members. With proper planning of the contingency reserves, we may only need to include a few of the more significant scenarios in the plan.

\section{PRINCIPLE OF BALANCE}

Project planning usually sets a limit on the utilization of resource capabilities supporting a project team. As was discussed before, the budget for a project supports all the project team's efforts and is usually preferred to be balanced by senior management. If an expense on one part of the budget is increased, then an expense on another part of the budget needs to be decreased. Using an approach similar to Chang et al. [6], we propose the following principle of balance (or balance principle) on the combined efforts associated with the resource capabilities of a project team. If the total or combined effort associated with resource capabilities is fixed, then it is more likely that the efforts associated with the capabilities supporting the rule and scope, respectively, would balance each other in the following sense. If the combined efforts associated with the capabilities supporting the rule increases, then the combined efforts associated with the capabilities supporting the scope decreases; if the combine efforts associated with capabilities supporting the scope increases, then the combined efforts associated with capabilities supporting the rule decreases. As was discussed before, the resource capability includes instances of time, project members, and capital. Efforts associated with each of the three instances are considered in this principle of balance.

Using also an approach similar to Chang et al. [6] we propose a model of the formula of a line, shown in Figure 2, which depicts how the efforts associated with resource capabilities supporting the scope and the efforts associated with resource capabilities supporting the rule balance each other as follows. Given a fixed total effort of resource capabilities $\mathrm{E}_{\text {total }}$, the formula describing the principle of balance is

$$
\mathrm{E}_{\text {rule }}+\mathrm{wE}_{\text {scope }}=\mathrm{E}_{\text {total }}
$$

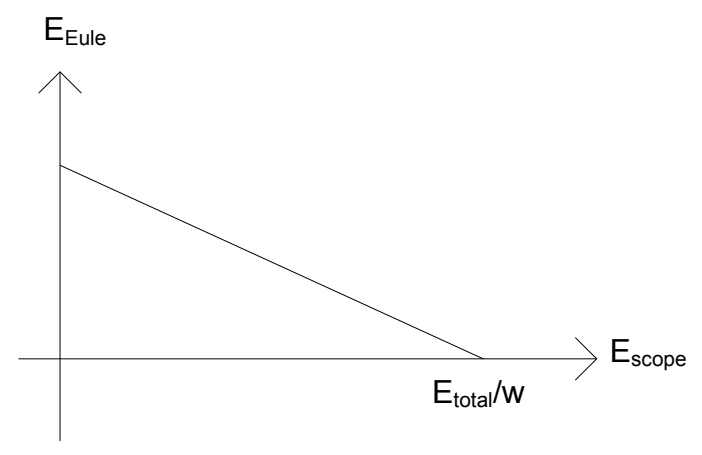

Fig. 2 Line Depicting Balance of Efforts Associated with Resource Capabilities
In the last equation, $E_{\text {rule }}$ is the combined effort of resource capability supporting the rule, $\mathrm{E}_{\text {scope }}$ is the combined effort of resource capability supporting the scope, and $\mathrm{w}$ is a weighting factor constant. Figure 2 is a graphical description of the formula. The range of values for $E_{\text {rule }}$ is $\left(0, E_{\text {total }}\right)$. The range of value for $E_{\text {scope }}$ is $\left(0, E_{\text {total }} / w\right)$. If $w=1$, then $E_{\text {rule }}$ and $E_{\text {scope }}$ have the same range. If $w>1$, then the range of $E_{\text {rule }}$ is wider than that of $E_{\text {scope }}$. If $w<1$, then the range of $E_{\text {rule }}$ is narrower than that of $E_{\text {scope }}$ A scenario describing Figure 2 will be covered in Section V.

Figure 2 is a simplified version that describes the principle of balance by a straight line. A more realistic version is that of a curve as shown in Figure 3, where $f\left(E_{\text {total }}\right)$ is a function of $\mathrm{E}_{\text {total }}$.

The function $\mathrm{f}$ can be nonlinear rather linear; i.e. the graph is a curve instead of a straight line. In this paper, we use technical factors required for a project as an example of a requirement in the scope and administrative procedures that need to be followed as an example of the rule. Suppose the budget for the project is fixed and in the middle of a project the client requests a significant improvement of the performance of an application, which requires the replacement of an existing technology by a newer technology. Suppose this request is accepted through the change management process. Since the budget is fixed and a replacement of the old technology requires additional capitals, labors, and time, some resource contingencies included in the budget may be used. Furthermore some rules specified in the administrative procedures may be lessened to save some costs and time that were already budgeted. For example, the administrative procedures require bids from at least three vendors that can provide the new technology. In order to speed up the evaluation effort, which requires costs of labor and time, the procedures may be lessened to accept the bid of one vendor that has a proven track record in supplying this new technology.

The last example, however, assumes that the project environment is mature enough to adapt to the change request and could plan quick changes in the administrative procedures, schedule, and work tasks and implement the changes. In reality, many project teams cannot adapt to a change request of a medium to large size without impacting the overall schedule and cost of the project.

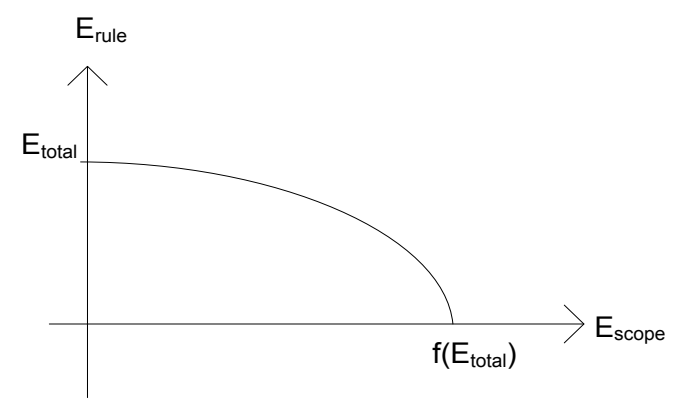

Fig. 3 Curve Depicting Balance of Efforts Associated with Resource Capabilities 


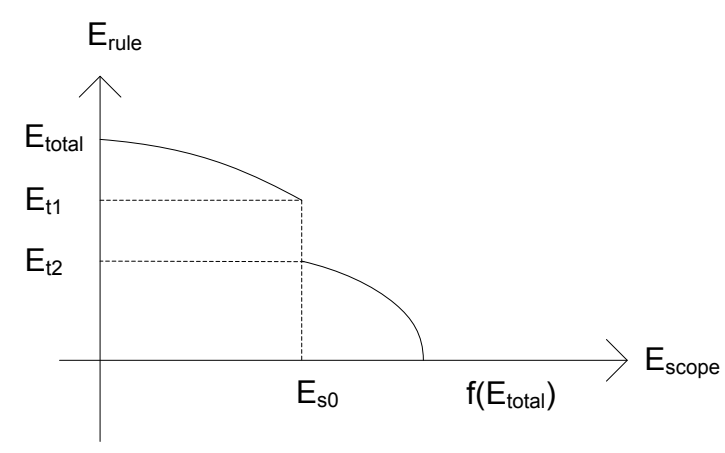

Fig. 4 Curve Depicting an Out of Balance of Efforts Associated with Resource Capabilities

As was described in Table 1, conflicts in one of seven categories may arise. Sometimes a small scope change may cause conflicts of a relatively disproportional magnitude that requires a drastic change of the rule. Figure 4 shows a scenario that a small increase of the scope causes a drastic relaxation of the rule. For an ease of discussion, we refer the resource capability supporting scope as the scope. We also refer the resource capability supporting the rule as the rule. In Figure 4, before the scope change is increased to the threshold point of $R_{s 0}$, the change of the rule is on a smooth curve. While the scope change is increased to a value close to $R_{50}$, the rule change is decreased to a value close to $R_{t 1}$. While the scope change is increased to a value beyond $R_{s 0}$, the rule change is decreased suddenly to a value close to $R_{t 2}$, which is much smaller than $R_{\mathrm{t} 1}$. We call such an out of balance phenomenon a breakdown phenomenon. Chang [12] addressed this in further details. An example of this phenomenon will be presented in Section $\mathrm{V}$.

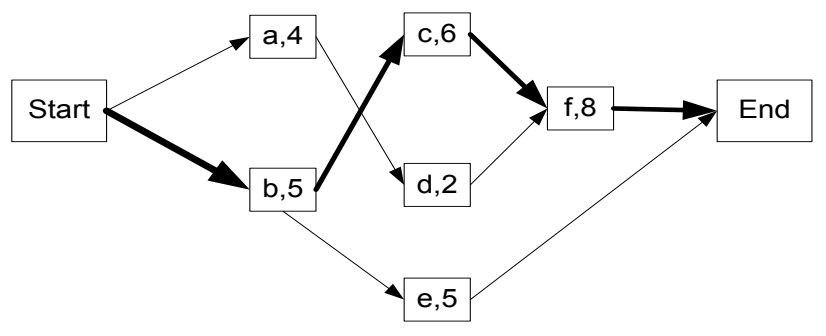

Fig. 5 Project Schedule on a Network Diagram

As an illustration on how the principle of balance can be applied, we consider a simplified project schedule in Figure 5, which depicts a project schedule on a network diagram with activity-on-node (AON) notations. A node such as "a,4" represents the activity a, which takes 4 days to complete. Since day is time, a part of the 4 days may be a reserved resource of contingency. In project management, a critical path on a network is a path that has the longest time that is sum of the times of the tasks on it. It can be determined that the path b-c-f in Figure 5 is the only critical path of that network. For a project of medium to large size, there could be potentially tens to hundreds of activities and hundreds to thousands paths. It would contribute to the success of a project significantly if the principle of balance on resource capability is maintained on all the critical paths associated with the project. Chang [12] discussed this in more details.

\section{SCENARIOS OF USING METHOdS OF PRINCIPLE OF BALANCE ON RESOURCE CAPABILITY IN SOFTWARE PROJECTS}

SEI [14] describes the CMMI's maturity level as a way of measuring the process improvement. Regarding to software projects, the maturity level helps appraise the effective level of methods of problem solving in software development processes. The methods described by the scenarios in this section illustrate an improved process that could help project managers realign project members more effectively in project teams.

As was stated earlier the resource capability may be time, project members, or capital. To illustrate the scenarios considered for this section, we consider efforts made by project members as the efforts supporting the rule, which is represented by the y-coordinate in Figures 6,7 , and 8 . We also consider efforts made through the utilization of time as the efforts supporting the scope, which is represented by the $\mathrm{x}$ coordinate in Figures 6, 7, and 8.

As some modern-day projects have smaller duration and smaller size of team members, consider the following project environment. There are three software projects that are concurrently being executed and managed by a project management office (PMO) headed by the project manager. Assume that the project members selected for the three projects have similar experiences, can transfer from one project to another and be productive instantly. Also assume that project members commit to make good efforts expected by the PMO. Project A initially has 6 members; project $\mathrm{B}$ initially has 3 members; project $C$ initially has 7 members. All three projects are scheduled to start at the same day and are scheduled to complete at the end of the seventh week. The initial plan is to transfer a member of project $A$ to project $B$ at the end of each week; no other transfer is planned. PMO sets up a contingency reserve of two persons. The number of persons on the list of contingency reserve can be altered based on how the analysis results of the second scenario discussed below are viewed by the PMO under the constraint of the project budget. Assume that the project members assigned to the projects are motivated to work overtime as a part of their efforts, if needed. Assume also that PMO does not set up any contingency reserve for time and capital.

The first scenario is that all three projects run smoothly and no contingency reserve is used. Figure 6 below, which is a special case of Figure 2 where $\mathrm{w}=1$, and Table 3 describe this scenario. In Table 3 change of value of y emulates that initially there is a team of 6 project members for project A. The change of value of $\mathrm{z}$ emulates that initially there is a team of 3 project members for project $B$. Each week a member transfers from project A to project B after completing his or 
her tasks. The change of value of $x$ emulates the accumulated time for completing project deliverables.

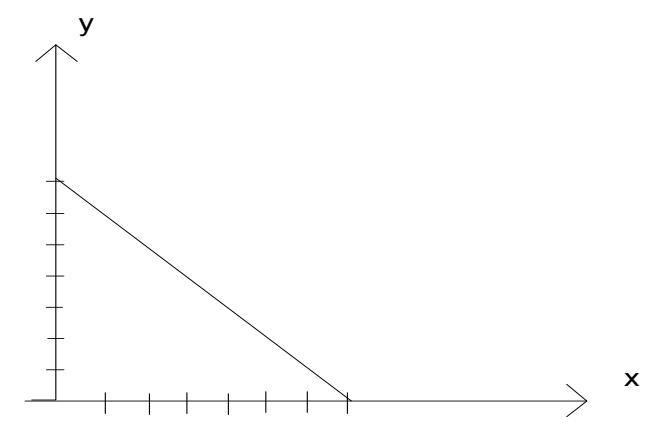

Fig. 6 Scenario 1 - graphical description

The equation describing Fig. 6 is listed below.

$$
\mathrm{x}+\mathrm{y}=7 \text {, for } 0<=\mathrm{x}<=7
$$

As was referred before, the $\mathrm{x}$ coordinate represents the efforts made through the utilization of time supporting the scope and the y coordinate represents the efforts made by the project members supporting the rule. The interpretation of the last equation is that the value of $\mathrm{x}$ describes the accumulated time for completing the deliverables specified in the scope for project $\mathrm{A}$; the value of $\mathrm{y}$ describes the number of project members needed to complete the remaining deliverables. At the beginning of the first week, $x$ is 0 because the accumulated time is 0 and $y$ is 7 because the total number of project members assigned to the beginning of project $A$ is 7 . As the $x$ value increases, the accumulated time increases and the $y$ value decreases because the number of project members needed decreases as the size of the remaining deliverables decreases. At the end of the $7^{\text {th }}$ week, $x$ is 7 because the accumulated time in completing all deliverables specified in the scope is 7. Also at the end of the $7^{\text {th }}$ week, $y$ is 0 because no project member is needed as all deliverables are completed.

The equation describing the transfer of a member from Project A to Project B at the end of each week is listed below.

$$
y+z=9 \text {, for } 1<=x<=7
$$

The interpretation of this equation is that each week the $y$ value is decreased by 1 and the $\mathrm{z}$ value is increased by 1 . Table 3 below describes the changes of the values of the number of project members.

TABLE 3 Scenario 1 - change of values

\begin{tabular}{|c|c|c|c|c|c|c|c|}
\hline $\mathrm{y}$ & 6 & 5 & 4 & 3 & 2 & 1 & 0 \\
\hline $\mathrm{x}$ & 1 & 2 & 3 & 4 & 5 & 6 & 7 \\
\hline $\mathrm{z}$ & 3 & 4 & 5 & 6 & 7 & 8 & 9 \\
\hline
\end{tabular}

$y=$ Number of project members left for project A at the end of each week $\mathrm{x}=$ Accumulated time for completed project deliverables

$\mathrm{z}=$ Number of project members for project $\mathrm{B}$ at the end of each week
The second scenario, referred hereafter as the out of balance scenario, is that at the third week, project $\mathrm{C}$ encounters an unplanned event and needs five more project members to help meet its schedule. An example of this unplanned event is that the user adds a new requirement to the list of deliverables or others. PMO decides to transfer, at the third week, three members from project $A$ to project $C$ and assigns the two persons on contingency reserve to project $C$; project $B$ receives no transfer. Table 4 below describes such a scenario. The meanings of $y, x$, and $z$ are the same as those for Table 3. The change of value of $v$ emulates that initially there is a team of 7 project members for project $C$ and on the third week three project members transfer from project $\mathrm{A}$ to $\mathrm{C}$ and in addition two persons from the contingency reserve are also assigned to project $C$. In this scenario, the resource capabilities supporting project $\mathrm{A}$ and $\mathrm{B}$ may be out of balance starting at the fourth week, which is indicated by the question marks in Table 4.

TABLE 4 Scenario 2 - change of values

\begin{tabular}{|c|c|c|c|c|c|c|c|}
\hline $\mathrm{y}$ & 6 & 5 & 2 & $?$ & $?$ & $?$ & $?$ \\
\hline $\mathrm{x}$ & 1 & 2 & 3 & 4 & 5 & 6 & 7 \\
\hline $\mathrm{z}$ & 3 & 4 & 4 & $?$ & $?$ & $?$ & $?$ \\
\hline $\mathrm{V}$ & 7 & 7 & 12 & 12 & 12 & 12 & 12 \\
\hline
\end{tabular}

$\mathrm{y}=$ Number of project members left for project A at the end of each week $\mathrm{x}=$ Accumulated time for completed project deliverables

$\mathrm{z}=$ Number of project members for project B at the end of each week $\mathrm{v}=$ Number of project members for project $\mathrm{C}$ at the end of each week

A meaning of a possible out of balance of combined efforts of resource capabilities in the above scenario, or a possible occurrence of a breakdown phenomenon, is that during the life cycle of a project some project members are required to work overtime by the PMO; but how much overtime hours that they can work per person may be uncertain. For this out of balance scenario, assume that project members can meet the full requirement of the overtime hours. In order to complete the scope in the 7th week without adding non-planned contingency reserves, the PMO may choose two solutions starting at the fourth week.

Solution 1 - during each of the remaining week, allocate a member from project $A$ to work half time in project $B$ and require the remaining team members of projects $A$ to work overtime at a higher rate.

Solution 2 - postpone the transfer of a remaining member of project $\mathrm{A}$ to project $\mathrm{B}$ during some weeks and require the remaining team members of project $A$ to work overtime at a lesser rate.

Figure 7 below, which is a special case of Figure 4, describes the case of the Solution 1. 


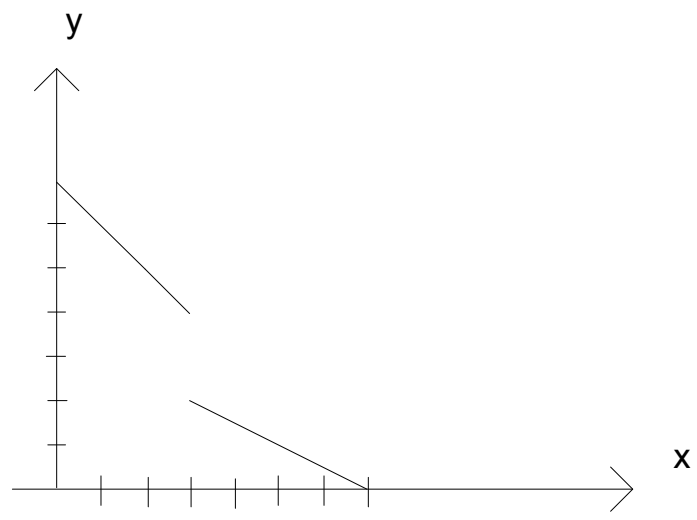

Fig. 7 Solution 1 of Scenario 2 - graphical description

The equations describing Figure 7 are listed below.

$$
\begin{aligned}
& x+y=7 \text { for } x<3 \\
& x+2 y=7 \text { for } x>=3
\end{aligned}
$$

Table 5 below describes the changes of the values of the number of project members; the variable y-actual, not the variable y-planned assumes the role of the variable $y$ in the above equations.

TABLE 5 Solution 1 of Scenario 2 - change of values

\begin{tabular}{|c|c|c|c|c|c|c|c|}
\hline $\mathrm{y}$ - planned & 6 & 5 & 4 & 3 & 2 & 1 & 0 \\
\hline $\mathrm{y}$ - actual & 6 & 5 & 2 & 1.5 & 1 & 0.5 & 0 \\
\hline $\begin{array}{c}\text { \% decrease } \\
\text { of y value }\end{array}$ & 0 & 0 & $100 \%$ & $100 \%$ & $100 \%$ & $100 \%$ & 0 \\
\hline $\mathrm{x}$ & 1 & 2 & 3 & 4 & 5 & 6 & 7 \\
\hline $\mathrm{z}$ & 3 & 4 & 4 & 4.5 & 5 & 5.5 & 6 \\
\hline $\mathrm{v}$ & 7 & 7 & 12 & 12 & 12 & 12 & 12 \\
\hline
\end{tabular}

$\mathrm{y}$ - planned $=$ planned number of project members left in project $\mathrm{A}$ at the end of each week

$\mathrm{y}$ - actual $=$ revised number of project members left in project $\mathrm{A}$ at the end of each week

$\mathrm{x}=$ Accumulated time for completed project deliverables

$\mathrm{Z}=$ Number of project members for project $\mathrm{B}$ at the end of each week

$\mathrm{v}=$ Number of project members for project $\mathrm{C}$ at the end of each week

The equations describing reduced transfers or non-transfer of a member from Project A to Project B at the end of each week are listed below.

$$
\begin{aligned}
& y \text {-actual }+z=9, \text { for } 1<=x<=2 \\
& y \text {-actual }+z=6, \text { for } 3<=x<=7
\end{aligned}
$$

The interpretation of these equations is that at the ends of week 1 and week 2, respectively, the y-actual value is decreased by 1 and the $\mathrm{z}$ value is increased by 1 , respectively. At the end of week 3 , the $\mathrm{y}$-actual value is decreased by 3 while the $\mathrm{z}$ value stays the same. This is because 3 members from project $\mathrm{A}$ transfer to Project C, but none transfer to Project B. From week 4 to week 6 , the y-actual value is decreased by 0.5 and the $\mathrm{z}$ value is increased by 0.5 . This means that during these three weeks a project member from project $\mathrm{A}$ is allocated at a half time basis to work in project B. The first three rows of the table also shows that from the third week on, the remaining project members in project A have to work $100 \%$ overtime hours to help keep up with the planned schedule.

Figure 8 below, which is also special case of Figure 4, describes the case of the Solution 2.

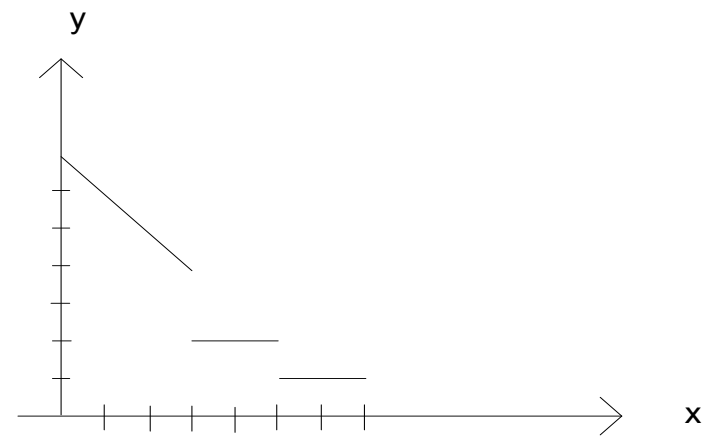

Fig. 8 Solution 2 of Scenario 2 - graphical description

The equations describing Figure 8 are listed below.

$$
\begin{aligned}
& x+y=7 \text { for } x<3 \\
& y=2 \text { for } 3<=x<5 \\
& y=1 \text { for } 5<=x<7
\end{aligned}
$$

The table below describes the changes of the values of the number of project members, where y-actual, not y-planned, assumes the role of the variable $y$ in the above equations.

TABLE 6 Solution 2 of Scenario 2 - change of values

\begin{tabular}{|c|c|c|c|c|c|c|c|}
\hline $\mathrm{y}$ - planned & 6 & 5 & 4 & 3 & 2 & 1 & 0 \\
\hline $\mathrm{y}$ - actual & 6 & 5 & 2 & 2 & 1 & 1 & 0 \\
\hline $\begin{array}{c}\text { \% decrease } \\
\text { of y value }\end{array}$ & 0 & 0 & $100 \%$ & $50 \%$ & $100 \%$ & 0 & 0 \\
\hline $\mathrm{x}$ & 1 & 2 & 3 & 4 & 5 & 6 & 7 \\
\hline $\mathrm{z}$ & 3 & 4 & 4 & 4 & 5 & 5 & 6 \\
\hline $\mathrm{V}$ & 7 & 7 & 12 & 12 & 12 & 12 & 12 \\
\hline
\end{tabular}

$\mathrm{y}$ - planned $=$ planned number of project members left in project $\mathrm{A}$ at the end of each week

$\mathrm{y}-$ actual $=$ revised number of project members left in project $\mathrm{A}$ at the end of each week

$\mathrm{x}=$ Accumulated time for completed project deliverables

$\mathrm{z}=$ Number of project members for project B at the end of each week

$\mathrm{v}=$ Number of project members for project $\mathrm{C}$ at the end of each week

Recall that y-actual assumes the role of $y$ in the last equations. The equations describing reduced transfers or non-transfer of a member from Project A to Project B at the end of each week are listed below.

$$
\begin{aligned}
& y \text {-actual }+z=9, \text { for } 1<=x<=2 \\
& y \text {-actual }+z=6, \text { for } 3<=x<=7
\end{aligned}
$$

The interpretation of these equations is that at the end of week 1 and the end of week 2, respectively, the y-actual value is decreased by 1 and the $\mathrm{z}$ value is increased by 1 , respectively. At the end of week 3 , the y-actual value is decreased by 3 
while the $\mathrm{z}$ value stays the same. This is, as described earlier, because 3 members from Project A transfer to Project C, but none transfer to Project B. Starting at week 4 and before the end of week 5 , the y-actual value stays as constant at 2 and $z$ value stays as constant at 4 . This means that during this time no member from project $A$ transfers out and project $B$ receives no new member. At the end of week 5, the y-value decreases by 1 and $\mathrm{z}$ value increase by 1 , which means that one member of project A transfers to project B. During week 6 and week 7, the $y$-actual value stays constant at 1 and $z$ value stays as constant at 5. This means that during this time no member from project $A$ transfers out and project $B$ receives no new member. The first three rows of the table also show that, to help keep up with the planned schedule, on the third and fifth weeks, the remaining project members in project $A$ have to work $100 \%$ overtime hours; on the fourth week, the remaining project members in project A have to work $50 \%$ overtime hours

As a future enhancement we can add rows of z-planned and z-actual to calculate the overtime hours that members of project B need to work from the third week on. For brevity, we do not pursue this matter here.

As was discussed before, the number of persons on the list of contingency reserve, which is 2 in the above out of balance scenario, can be altered based on how the analysis results of the above scenario are viewed by the PMO under the constraint of the project budget. After several iterations, the PMO can alter the number to a more optimal one.

\section{EXTEND THE APPROACH OF PRINCIPLE OF BALANCE OF COMBINED EFFORTS OF RESOURCE CAPABILITY TO MORE GENERAL CASES}

The project environment described in the scenarios in Section $\mathrm{V}$ and the approach used in using the contingency reserves and obtaining the Solutions 1 and 2 there can be extended to more general cases. This approach is based on the principle of balance of the efforts of resource capability described in Section IV. For example, only two types of resources: project members and time were considered in the two scenarios. The same approach can be extended to cases that include the third type: capital. Only the unplanned event that project $\mathrm{C}$ needs more project members starting at the third week is considered in the out of balance scenario of Section V. Other unplanned events may also be considered. If a project manager identifies some critical scenarios from the 64 scenarios referred in the description following Table 2 in Section III, the same approach can be applied to them. Moreover, the approach may be applicable to projects of disciplines other than software and information engineering.

\section{CONCLUSIONS}

Project managers usually include contingency reserves in the project plan. Reserves are about resources that include time, person, and capital. Properly estimating the quantities of contingency reserves needed is an important task for project manager to do. Or it is an important problem to solve. This is especially important in managing modern-day projects, which tend to use less resource but are more dynamic in the sense that changes such as user requirements occur more frequently during the project life cycle. Section II of the paper covers the notion of three Elements of Methods or Problem Solving (EMPS). These elements, first proposed in Chang [5], are at various levels of abstraction. Section III covers the notion of efforts of resource capability supporting the EMPS. We propose the resource capability formula, which expresses contingency reserve as a part of the resource capability. Section IV covers the principle of balance of efforts associated with the resource capability. In Section V, we introduce a new approach based on the principle of balance to manage the use of contingency reserve and illustrate it with two scenarios. The concept of the approach is concise but rigorous. As is shown by the two solutions in Section V, it is also effective. It may be applied for planning and managing contingency reserve of modern-day projects in software and information engineering or other types of projects in general.

\section{REFERENCES}

[1] Project Management Knowledge. Contingency Reserve. Retrieved in January 2012 from http://project-management-

knowledge.com/definitions/c/contingency-reserve/.

[2] G. Pólya, How to Solve It: A New Aspect of Mathematical Method, Princeton, New Jersey: Princeton University Press, 1945. http://press.princeton.edu/titles/669.html

[3] Princeton University Press. Princeton University Press Centenary, 19052005. Retrieved in January 2012 from http://press.princeton.edu/about_pup/PUP100/centgreeting.html

[4] R. Milner, "Elements of Interaction," Communications of the ACM vol. 36, no. 1, pp. 78-89, January 1993.

[5] P. H. Chang, "How to Solve It - Elements of Methods of Problem Solving," Proceedings of the IPSI Tokyo Conference, University of Tokyo, Tokyo, Japan (May-June, 2007).

[6] P. H. Chang and M. Blaha, "Elements of Methods of Problem Solving and the Resource Capability in Software Engineering," Proceedings of the IEEE EIT 2009 Conference, University of Windsor, Windsor, Canada (June, 2009), pp. 84-89.

[7] A. J. Shenhar, "One Size Does Not Fit All Projects: Exploring Classical Contingency Domains," Journal of the Institute for Operations Research and the Management Science, Vol. 47, No. 3, pp. 394-414, March, 2001.

[8] G.B. Davis, "Strategies for Information Requirements Determination," IBM Systems J., vol. 21, No. 1, pp. 4-30, 1982.

[9] H. Zhang, B. Kitchenham, R.; Jeffery. "Planning Software Project Success with Semi-Quantitative Reasoning," Proceeding of Australian Software Engineering Conference, ASWEC, pp. 369-378, 2007.

[10] J. Ropponen, K. Lyytinen. "Components of software development risk: how to address them? A project manager survey," IEEE Transactions on Software Engineering, Vol. 26, Issue 7, pp. 98-112, 2000.

[11] H. Steyn. "Change Management and the New Industrial Revolution," IEMC '01 Proceedings, pp. 400-405, 2001.

[12] P. H. Chang, "Modelling Elements of Methods of Problem Solving in Software and Information Engineering Projects," Proceeding of the Third International Conference on Educational Technology and Training conference, Wuhan, China, November 2010

[13] H. J. Thamhain and D. L. Wilemon, "Conflict Management in Project Life Cycles," Sloan Management Review, Summer 1975.

[14] SEI (Software Engineering Institute), Carnegie-Mellon University. CMMI for Development, Version 1.2. Retrieved in January 2012 from http://www.sei.cmu.edu/reports/06tr008.pdf. 


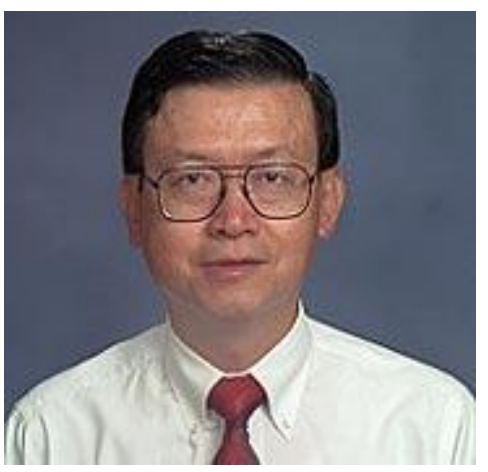

Peter H. Chang is an associate professor in Information Systems of the College of Management of Lawrence Technological University in Michigan, U.S.A. His research interests include software engineering, problem solving methodology, cloud computing, Service-Oriented Architecture, objectoriented analysis, modeling, and design, data management, Web middleware and server technologies, and data and Web securities. Peter received a $\mathrm{PhD}$ from the University of Minnesota, Minnesota, U.S.A. He is a member of IEEE and ACM. 